Title:

Author(s):

Submitted to:
Optical-Fiber Laser Amplifier for UltrahighSpeed Communications

RECEIVED

APR 181996

OSTI

Timothy Gosnell, MST-10

Ping Xie, CST-1

Nigel Cockroft, CST-1

DOE Office of Scientific and Technical Information (OSTI)



Los Alamos National Laboratory, an affimative action/equal opportunity employer, is operated by the University of Calliornia for the U.S. Department of Energy under contract W-7405-ENG-36. By acceptance of this anicle, the publisher recognizes that the U.S. Government retains a nonexclusive, royaltyfree license to publish or reproduce the published form of this contribution, or to allow others to do so, for U.S. Government purposes. The Los Alamos National Laboratory requests that the publisher identity this article as work performed under the auspices of the U.S. Department of Energy. 


\section{DISCLAIMER}

Portions of this document may be illegible in electronic image products. Images are produced from the best available original document. 


\title{
Optical-Fiber Laser Amplifier for Ultrahigh-Speed Communications
}

Timothy Gosnell*, Ping Xie, and Nigel Cockroft

\begin{abstract}
This is the final report of a three-year, Laboratory-Directed Research and Development (LDRD) project at the Los Alamos National Laboratory (LANL). The project objective was to develop a praseodymium-based $1.31-\mu \mathrm{m}$ fiber amplifier that can be optically pumped with off-the-shelf semiconductor diode lasers. Development of optical amplifiers for the $1.31-\mu \mathrm{m}$ communications window is motivated by the push towards "all-optical" networks that will support multigigabits per second communication rates. Our approach exploited radiationless energy transfer from optically pumped $\mathrm{Yb}^{3+}$ ions co-doped with $\mathrm{Pr}^{3+}$ into a fluorozirconate glass (ZBLAN). We obtained a gain of approximately 10 on a $1.31-\mu \mathrm{m}$ amplifier, a value too low for practical applications. In two spin-off applications, all-solid-state operation at all four output wavelengths was achieved in the development of a four-color visible laser, and laser cooling of a solid material was demonstrated for the first time in the development of a fluorescent cryogenic refrigerator.
\end{abstract}

\section{Background and Research Objectives}

Next-generation telecommunications systems will be based on the transmission of information-bearing optical signals through silica-glass fiber waveguides. Although signal attenuation in silica fiber is actually less than in free air, optical communications systems still require repeater stations every $50 \mathrm{~km}$ to compensate for scattering and absorption losses. Existing optical networks accomplish this task through optical-to-electrical signal decoding, followed by optical regeneration and retransmission over a subsequent fiber link to the next repeater. These optoelectronic regenerators are slow, complex, and sacrifice the greatest advantage offered by optical communications-wavelength multiplexing. There has, therefore, existed strong motivation for the development of all-optical systems in which an appropriate optical amplifier is used to refresh optical signals directly.

*Principal investigator, e-mail: gosnell@lanl.gov 
In 1987, a major advance was accomplished in this field when erbium-doped optical fibers amenable to diode-laser pumping were first demonstrated as viable amplifiers for the $1.55-\mu \mathrm{m}$ communications window. The success of the erbium-fiber amplifier has set the stage for development of amplifiers for the $1.31-\mu \mathrm{m}$ communications window. Significantly, such an amplifier is expected to displace the erbium amplifier in all contexts except intercontinental communications for the following reasons: (1) most of the existing worldwide optical communications infrastructure operates with a $1.31-\mu \mathrm{m}$ carrier wave, (2) diode transmitter oscillators for $1.31 \mu \mathrm{m}$ are more technically mature and easier to manufacture than $1.55-\mu \mathrm{m}$ oscillators, and (3) ever increasing demands for information capacity-especially in computernetwork applications-will focus enormous pressure on the development of $1.31-\mu \mathrm{m}$ systems.

A major breakthrough in $1.31-\mu \mathrm{m}$ fiber amplification was reported in 1992 by researchers at Nippon Telephone and Telegraph (Japan) where an optical gain of 7000 was demonstrated in an eight-meter-long fluorozirconate-glass fiber doped with trivalent praseodymium ions. Since that time, praseodymium-doped fluorozirconate glass has rapidly seized de facto status as the gain medium upon which $1.31-\mu \mathrm{m}$ fiber amplifiers will be based. Unfortunately, there exists a serious impasse to rapid commercialization of the praseodymium amplifier-it must be optically pumped at $1.02-\mu \mathrm{m}$, a wavelength for which no viable highpower diode laser now exists.

Our approach to the praseodymium pumping problem was to exploit a solid-state radiationless energy transfer mechanism by which an optically pumped "donor" ion excites a proximate praseodymium ion, in the process populating the upper electronic state of the requisite $1.31-\mu \mathrm{m}$ amplification transition. The crucial advantage offered by this donoracceptor excitation mechanism is that promising donor ions exist that can be optically pumped at $790 \mathrm{~nm}$, a wavelength for which the most highly developed high-power diode lasers are readily available at low cost.

\section{Importance to LANL's Science and Technology Base and National R\&D Needs}

The demand for high-performance computer networking technology is unsurpassed, especially within the Department of Energy (DOE) complex. Applications to nuclear weapons simulations alone created the U.S. supercomputer industry; these and other complex defenseand energy-related computer simulations have made the DOE complex the largest consumer of high-performance computers in the world. The development of successful high-speed localarea, metropolitan-area, and wide-area digital communications networks linking the Defense Programs (DP) sites will increase capabilities in computer-integrated design and manufacturing 
and in computer simulation of nuclear tests. Massively parallel and vector supercomputers, storage servers, and individual workstations-potentially located at widely separated DOE sites-could be dedicated to single computations as expensive resources are centralized rather than separately duplicated.

Several computer networking activities at the national laboratories are already in progress. In conventional electronic links, Lawrence Livermore National Laboratory (LLNL) and Sandia National Laboratory (SNL) participate in the XUNET gigabit research network experiment. LANL is a major participant in the CASA gigabit experiment, which implements the Laboratory's High Performance Parallel Interface (HiPPI) on a wide-area network. LLNL has an active internal program to develop optical local-area-network interfaces and switches (Fibre Channel), an effort analogous to a LANL program, but which exploits HiPPI technology. SNL has a major internal program to link its two sites via high-speed asynchronous-transfer-mode (ATM) switches (a data packet networking technology). Oak Ridge National Laboratory (ORNL) is demonstrating computer-integrated manufacturing techniques for improving the productivity of regional machine shops, a program that includes a communications link between $\mathrm{Y}-12$ and several regional defense manufacturers reachable via the Internet.

\section{Scientific Approach and Results}

In the first year of the project, both pulsed and laser-induced fluorescence techniques were used to probe the energy transfer dynamics of donors and acceptors in bulk fluorozirconate glasses. Major accomplishments include:

a. Our initial choice of a donor ion ( $\mathrm{Tm}^{3+}$ ) was proven to populate the desired praseodymium state, but an unexpected back-transfer effect from the acceptor to the donor quenched the 1.31- $\mu \mathrm{m}$ fluorescence.

b. We investigated two other potential donors, one of which failed $\left(\mathrm{Nd}^{3+}\right)$, but the other of which proved a great success $\left(\mathrm{Yb}^{3+}\right)$.

c. The quantum efficiency for conversion of pump photons into excited-state $\mathrm{Pr}^{3+}$ was determined to be 60 percent in an unoptimized $\mathrm{Yb}^{3+} / \mathrm{Pr}^{3+}$ double-doped sample.

d. Time-resolved fluorescence measurements were successfully explained with a "direct-transfer" model of the energy-transfer dynamics. These results have allowed us to make direct quantitative comparisons with the $\mathrm{Yb}^{3+} / \mathrm{Pr}^{3+}$ donor/acceptor system developed by the Japanese and show that the performance of this ion combination for producing the desired population inversion on the 
amplifying transition is much better than reported by other workers. This "improvement" is the basis for a patent application currently under review.

In the second year of the project, the $\mathrm{Yb}^{3+} / \mathrm{Pr}^{3+}$ system was studied in detail and two spin-off applications were developed. Major accomplishments include:

a. The optimum concentrations of $\mathrm{Pr}^{3+}$ and $\mathrm{Yb}^{3+}$ were determined to be $0.3 \mathrm{wt} \%$ and $2 \mathrm{wt} \%$, respectively. This combination gave a net quantum efficiency for population of the desired $\mathrm{Pr}^{3}+$ energy level of 56 percent.

b. A custom double-doped ZBLAN fiber was procured from Le Verre Fluore (France). This fiber was used in one of the spin-off experiments to demonstrate blue, green, orange, and red laser output from the same piece of fiber and pumped with a single infrared wavelength, the first time this has ever been accomplished. A patent application for this invention has been submitted.

c. The second spin-off application involves singly-doped ZBLAN bulk glasses and fibers and relates to the optical cooling of solids. A patent application has been submitted for our invention based on this concept of a laser pumped cryogenic refrigerator.

In the third and final year of the project, we performed an assessment of the viability of the 1.31- $\mu \mathrm{m}$ amplifier, but the main focus was the two spin-off applications. Major accomplishments include:

a. The gain of the $1.31-\mu \mathrm{m}$ amplifier was measured to be approximately 10 , a value that is too low to be practical in a real-world application. Nevertheless, the essential efficiency of the energy-transfer process we optimized in the early months of the project should be largely transferable to different glass host materials currently in commercial development. When these materials become available, the gain of the amplifier should substantially improve, perhaps to the point of being commercially viable.

b. The major acomplishment in the development of the solid-state laser based on the same fiber as was used in the $1.31-\mu \mathrm{m}$ amplifier development was the achievement of all-solid-state operation. In this experiment, a commercial semiconductor diode laser was used to obtain for the first time multicolor visible output in an all-solidstate device.

c. The major accomplishment in the development of laser-cooled solids and fluorescent refrigeration was the first demonstration of true net cooling of a solid material exposed to laser light. This result has generated tremendous interest and should lead to significant external funding over the next several years. A patent was granted for this invention in FY95. 


\section{DISCLAIMER}

This report was prepared as an account of work sponsored by an agency of the United States Government. Neither the United States Government nor any agency thereof, nor any of their employees, makes any warranty, express or implied, or assumes any legal liability or responsibility for the accuracy, completeness, or usefulness of any information, apparatus, product, or process disclosed, or represents that its use would not infringe privately owned rights. Reference herein to any specific commercial product, process, or service by trade name, trademark, manufacturer, or otherwise does not necessarily constitute or imply its endorsement, recommendation, or favoring by the United States Government or any agency thereof. The views and opinions of authors expressed herein do not necessarily state or reflect those of the United States Government or any agency thereof. 